\title{
Lugares e não lugares em Marc Augé
}

Teresa Sá

As transformações que atualmente ocorrem na vida cotidiana de cada um de nós, e que resultam do processo de globalização, refletem-se na nossa relação com o espaço, o tempo e os outros. As duas noções analisadas por Marc Augé, "lugar antropológico/não lugar" ${ }^{1}$, permitem-nos tomar consciência dessas transformaçôes, que surgem de uma forma aparentemente "natural" e vão substituindo a cidade antiga pela emergência de uma "nova cidade".

Entendemos essas duas noçôes - "lugar antropológico"2 e "não lugar"3 como "tipos ideais" (cf. Weber, [1922]* 1971), que representam os espaços dominantes respectivamente das sociedades sem escrita e da sociedade contemporânea ocidental.

O que a noção de "não lugar" nos permite é algo menos rígido e talvez menos rigoroso sob o ponto de vista científico, exatamente pela ambiguidade da sua definição, como veremos neste texto. Porém, mais interessante sob o ponto de vista da análise social é encontrar uma imagem do todo que não é a recomposição minuciosa das partes. Corresponde empiricamente a um conjunto de construçôes com características muito diferentes - aeroportos, cadeias de hotéis, hipermercados, autoestradas etc. Augé não analisa exaustivamente nenhum desses tipos de espaço, mas procura perceber o que é comum a todos eles e de que modo sua proliferação provoca mudanças na organização social-econômica-simbólica da sociedade e, portanto, na vida cotidiana dos indivíduos: "O problema é descobrir aquilo que é comum a

1. Encontramos nos estudos urbanos outras noçôes semelhantes: heterotopias (Michel Foucault); lugar e espaço (Michel De Certeau); nonplace (Melvin Webber); cyberspace (Françoise Choay); espaço de fluxos e espaço dos lugares (Manuel Castells).

2. Que Marc Augé (2005) define como um espaço identitário, relacional e histórico. O não lugar é o seu oposto: espaços não identitários, não relacionais e não históricos.

3. Termo utilizado pela primeira vez por Jean Duvignaud em Lieux et non-lieu (Paris, Galilée, 1977).

* A data entre colchetes refere-se à edição original da obra. Ela é indicada na primeira vez que a obra é citada. Nas demais, indica-se somente a edição utilizada pelo autor (N. E.) 
4. Edição brasileira: Vida para consumo: a transformação das pessoas em mercadoria. Rio de Janeiro, Zahar, 2008 (N. E.). todos. É um problema, poder-se-ia dizer, de tradução, de traduzir o que está dito numa linguagem [...] numa expressão de uma linguagem diferente" (Lévi-Strauss, 1987, p. 21). A alteração da linguagem no nível da construção desses espaços implica também uma alteração da linguagem social daqueles que vão ocupá-los. A relação não é determinista, como veremos, mas ela existe.

\section{A alteridade ou "nós e o outro"}

Ao ler os vários livros publicados por Marc Augé a partir de 1992, quando se refere pela primeira vez à noção de "não lugar", percebemos que esse conceito está presente em quase todos os seus trabalhos, como se incorporasse qualquer coisa de fundamental que acompanha seu pensamento sobre a sociedade contemporânea. Parece que o que está em jogo na construção dos espaços e na sua própria vivência, que permite a aceleração do tempo e a virtualização do espaço, é a transformação de nós mesmos em outros, algo que realizamos mas do qual não nos damos conta: "todos nós temos a impressão de estarmos sendo colonizados, mas sem que saibamos ao certo por quem" (Augé, 1998, p. 7). Zygmunt Bauman, em Vida para consumo ${ }^{4}$, desenvolve a tese da passagem da "sociedade de produtores" para a "sociedade de consumidores" e refere-se a Siegfried Kracauer como um autor que conseguiu nos anos de 1920 ver o invisível e perceber como fundamental aquilo que parecia passageiro. Afirmava Kracauer, em 1929:

O êxito dos salōes de beleza surge em parte de preocupações existenciais, e o uso de produtos de beleza nem sempre é um luxo. Com medo de serem descartados como ultrapassados, tanto as senhoras como os cavalheiros tingem o seu cabelo, enquanto os quarentōes se dedicam a fazer esporte para continuar magros. "Como ser bonito" é o título de um folheto recente que apareceu no mercado, e nos jornais é publicado o caminho que cada um deve seguir "para se manter jovem e bonito agora e para sempre" (apud Bauman, 2007, p. 18).

Assim como Kracauer conseguiu antever a importância do marketing do princípio do século XX, que se ajusta às "preocupaçôes existenciais" características de uma sociedade onde o "individualismo" tem um peso cada vez maior, Marc Augé centra-se nos não lugares para tentar perceber de que forma certos espaços construídos, cujo principal objetivo é permitir "fazer cada vez mais coisas em menos tempo", estão nos transformando em outros. 
Se é verdade que a história da humanidade é um acentuar de transformaçôes que ocorrem ao longo do tempo, o autor alerta para a quantidade e a rapidez de certas transformações atualmente em curso. Essa situação permite cada vez menos vermo-nos simultaneamente enquanto ator e espectador, pois o ritmo das mudanças ultrapassa o ritmo da vida - nada está parado à nossa espera, tudo muda constantemente.

Se o lugar antropológico representa um tempo passado e o não lugar um provável futuro, pensar a relação entre os dois é de certo modo pensar uma realidade que se joga entre o que fomos/somos e aquilo em que poderemos nos tornar, ou melhor, aquilo em que estamos nos tornando5.

Marc Augé, ao analisar a relação entre lugar antropológico e não lugar na sociedade contemporânea, transporta para o espaço a questão da alteridade: "Se a tradição antropológica ligou a questão da alteridade (ou da identidade) à do espaço, é porque os processos de simbolização colocados em prática pelos grupos sociais deviam compreender e controlar o espaço para se compreenderem e se organizarem a si mesmos" (Augé, 1994b, p. 158). O exemplo já clássico de Lévi-Strauss em relação à aldeia dos Bororos mostra como a localização espacial das palhoças estava diretamente relacionada com a sua organização social, política e econômica. Quando os missionários salesianos mudaram sua disposição, colocando-as em linha reta e substituindo sua forma tradicional circular, os Bororos perderam o sentido das tradições e da sua própria cultura.

A pergunta que parece estar sempre subjacente ao pensamento de Augé é saber de que forma os "não lugares" podem provocar uma perda de nós mesmos como grupo e sociedade, prevalecendo agora apenas o indivíduo "solitário".

Os três tipos de alteridade apresentados pelo autor - social (diferença de sexo, idade, classe social etc.), íntima (aquilo que cada um consegue fazer de si próprio) e completa (o estrangeiro, entendido como o inimigo) (cf. Idem, ibidem) - sempre existiram na história das sociedades. Mas o que se passa hoje, no período que Augé denominou sobremodernidade, marcado pelos excessos de acontecimentos, imagens e referências espaciais e individuais (cf. Augé, 1994a), é a perda da categoria do outro.

Se, por um lado, os "não lugares" permitem uma grande circulação de pessoas, coisas e imagens em um único espaço, por outro transformam o mundo em um espectáculo com o qual mantemos relaçóes a partir das imagens, transformando-nos em espectadores de um lugar profundamente codificado, do qual ninguém faz verdadeiramente parte. Como afirma
5. As dicotomias vizinhança/ anonimato, heterogeneidade/ homogeneidade, inclusão/exclusão, lugar/não lugar etc. são ferramentas que permitem pensar essa transformação de nós em outro. 
Gérard Althabe, a relação de cada um com o planeta é uma relação direta, sem mediadores, é "a imagem vertiginosa da solidão" (Idem, pp. 135-136). A relação com o outro é minimizada em detrimento da relação com nós mesmos - não temos tempo para estar/parar, estamos de passagem, em viagem, espaço onde a ação racional se impõe à vida de qualquer coisa: "O não lugar é o espaço dos outros sem a presença dos outros, o espaço constituído em espectáculo” (Augé, 1994b, p. 167).

O desejo de tudo fazermos em um período de tempo cada vez mais curto, de não perdermos nada do que se passa já não só à nossa volta, mas também no mundo, não permite a vida nos espaços físicos que ocupamos. Os espaços físicos transformam-se em meios que possibilitam a interação no espaço virtual: nunca estamos onde estamos fisicamente - contatos, informações, publicidade (celulares, computadores, cartazes, monitores, alto-falantes)-, tudo isso nos transporta para outras realidades, problemas, alegrias, desejos, nos faz sonhar sem o sonho.

Essa substituição do espaço real pelo espaço virtual surge como um constrangimento que parece libertar-nos e manifesta-se nas transformaçōes que estão a emergir na organização do espaço, das quais não nos damos conta facilmente, porque parecem a resposta mais simples à resolução de nossos problemas do dia a dia. Pensamos com facilidade no que se ganha, mas não no que se perde. Daí que Augé se refira à importância dos antropólogos para analisar o mundo contemporâneo hoje, exatamente porque estes desde sempre analisaram a alteridade e "foram sempre mais sensíveis à beleza daquilo que se desmorona do que à amplitude do que se anuncia" (Augé, 2003, p. 16).

É necessário olharmo-nos criando uma distância entre nós e nós, distância essa que o antropólogo tem naturalmente quando estuda uma sociedade arcaica, visto que ali ele está face a face com uma realidade marcadamente diferente, mas que deve procurar criar ao estudar a sociedade ocidental.

\section{Lugar e não lugar entrelaçados}

Marc Augé parte de uma concepção do espaço cujas bases são encontradas no pensamento de Georges Simmel, para quem o espaço físico e o espaço social estão juntos, um não existe sem o outro: "A ação recíproca faz do espaço, até então vazio e nada, qualquer coisa para nós, preenche-o enquanto ele a torna possível" (Simmel, [1908] 1992, p. 601). A dicotomia lugar/não lugar é de certo modo uma dicotomia dupla, pois o que está em 
causa são simultaneamente os espaços construídos e os espaços vividos. Os primeiros, que correspondem ao "não lugar", são aqueles que possibilitam a aceleração do tempo; os segundos têm a ver com as relações que aí acontecem. $\mathrm{O}$ autor estabelece assim um contraste entre as interações que se praticam nos "não lugares", denominados relações de "solidão", associadas à ideia de "contratualidade solitária", e as que se praticam nos "lugares antropológicos", denominados relações de sociabilidade. Lembremos do que se passa quando vamos a um grande hipermercado:

[...] as grandes superfícies nas quais o cliente circula silenciosamente, consulta as etiquetas, pesa os legumes ou a fruta numa máquina que lhe indica, juntamente com o peso, o seu preço, e depois estende o cartão de crédito a uma mulher jovem também ela silenciosa, ou pouco faladora, que submete cada artigo ao registro de uma máquina decodificadora antes de verificar o bom funcionamento do cartão de crédito (Augé, [1992] 2005, p. 84).

Em um livro posterior, referindo-se ao supermercado, o autor afirma: "circula-se nele de um corredor de prateleiras para outro e dialoga-se tão só com as etiquetas" (Augé, [2003] 2006, p. 124). Uma ida à mercearia de bairro (cf. Giard e Mayol, 1980), que ainda conseguimos presenciar ou recordar, implica um tipo de interação com os outros (dono da loja, empregados, vizinhos) completamente diferente.

Mas as coisas complicam-se, porque é impossível esquematizar dessa forma simples a realidade social. Assim, um não lugar como espaço empírico pode ser sob o ponto de vista social simultaneamente um "lugar antropológico" (e vice-versa).

Se definirmos o não lugar não como um espaço empiricamente identificável (um aeroporto, um hipermercado ou um monitor de televisão), mas como o espaço criado pelo olhar que o toma como objeto, podemos admitir que o não lugar de uns (por exemplo, os passageiros em trânsito num aeroporto) seja o lugar de outros (por exemplo, os que trabalham nesse aeroporto) (Augé, 2006, p. 116).

Se é verdade, como afirma Kevin Lynch (2007, p. 151), que "o espaço sugere ação, ao mesmo tempo que a limita", são as pessoas em última instância que interagem no meio desse jogo de possibilidades e que determinam a experiência urbana. $\mathrm{O}$ processo de interação social permite a cada indivíduo uma possibilidade de "jogo", que parte das diferentes configuraçôes (cf. Elias, 
6. Conceito desenvolvido por Marc Augé, diretamente relacionado com as dimensōes de circulação, consumo e comunicaçāo, em contraste com as dimensōes identitárias, históricas e relacionais que caracterizam os lugares antropológicos.
1999, p. 78) que cada um ocupa, o que permite até contornar as regras preestabelecidas. Lembremos De Certeau, quando defende que o transeunte consegue inventar novos caminhos para além daqueles que a ordem espacial possibilita: "Assim, Charlie Chaplin multiplica as possibilidades da sua bengala: faz outras coisas com a mesma coisa, ultrapassando os limites que fixavam sua utilização às determinações do objeto" (De Certeau, 1980, p. 181). Mas, se essa margem de liberdade é sempre possível para cada indivíduo considerado isoladamente, os não lugares são mais constrangedores do que libertadores, devido à racionalidade subjacente da sua organização, à excessiva codificação do espaço, ao poder das imagens e do espetáculo a elas associado - trata-se de um espaço de circulação e movimento, de passagem, onde o que está em causa é o objetivo que se quer atingir (chegar a um local, comprar um objeto). Os "não lugares" são espaços multifuncionais, cujo objetivo é possibilitar a cada um fazer cada vez mais coisas em um mesmo espaço. São espaços para consumir, e para criar "novas necessidades" (publicidade, informação). São eles que caracterizam a sobremodernidade ${ }^{6}$ :

Mas, na medida em que o não lugar é o negativo do lugar, torna-se de fato necessário admitir que o desenvolvimento dos espaços da circulação, da comunicação e do consumo é um traço empírico pertinente da nossa contemporaneidade, que esses espaços são menos simbólicos do que codificados, assegurando neles toda uma sinalética e todo um conjunto de mensagens específicas (através de monitores, de vozes sintéticas) na circulação dos transeuntes e dos passageiros (Augé, 2006, p. 115).

Se, por um lado, no pensamento de Marc Augé parece haver alguma nostalgia em relação aos "lugares antropológicos", por outro, também existe uma atração pelos não lugares, pois permitem um distanciamento do cotidiano, da rotina, uma experiência de anonimato:

Se, como muitos, me sinto satisfeito por passar um período na casa de amigos, por me beneficiar da sua hospitalidade, por aflorar a sua intimidade, as longas viagens de trem ou de avião, as estações e os aeroportos e até mesmo a elegância estereotipada dos hotéis internacionais proporcionam-me um prazer diferente, ligado, sem dúvida, a tudo aquilo que também poderíamos denunciar como sinal de uniformização e despersonalização crescentes: o anonimato, a solidão, a redução ao estado de agente de ligação cuja identidade é definida pelo trajeto [... ] ligado igualmente a todos os benefícios secundários de um parênteses: o futuro limitado à duração da estadia, da viagem ou da correspondência, o desprendimento das obrigaçôes cotidianas, a 
distância, no sentido próprio e no figurado, em relação ao ponto de partida - no conjunto, um certo estado de inocência (Augé, 1989, pp. 137-138) ${ }^{7}$.

O autor, mais tarde, faz uma comparação entre as oposições lugar/não lugar e cheio/vazio, argumentando que o lugar antropológico está carregado de sentido social, onde tudo se justifica, mas acrescenta: "A liberdade individual não tem grande significado em meios fechados, como costuma se dizer, e a sobrecarga de sentido (o fato de o menor movimento ser interpretado) tem por corolário essa ausência de liberdade, esse vazio" (Augé, 2006, pp. 127-128). Por outro lado, os não lugares, espaços de comunicação, circulação e consumo, estão demasiado cheios de pessoas e de funções, onde o global penetra no local, marcados por uma plurifuncionalidade: um grande aeroporto é também um hipermercado, um lugar de informação, de publicidade (cf. Idem, pp. 129-130). Trata-se, assim, em ambos os casos, "lugar antropológico" e "não lugar", de espaços simultaneamente cheios e vazios.

Como o autor refere em um livro mais recente, o que sempre está em causa em qualquer sociedade é a oposição entre "sentido social" e liberdade. Se privilegiamos o "sentido", relação entre uns e outros como está definida $a$ priori a partir da constituição da sociedade e da cultura, perde-se a liberdade, ou seja, o indivíduo. Se privilegiamos o desejo individual, perde-se a relação com a sociedade. "Nem a loucura totalitária nem a loucura da solidão sabem orientar e comandar a vida social" (Augé, 2011, p. 85).

O que parece inquietar Augé é a súbita e rápida substituição dos lugares pelos não lugares, tornando a cidade cada vez mais um espaço de anonimato e solidão, ou seja, fazendo prevalecer a liberdade (indivíduo) sobre o sentido (sociedade).

Do espaço público ao não lugar: o centro comercial é um não lugar?

Um dos exemplos apresentados por Marc Augé como um "não lugar” são os grandes centros comerciais ${ }^{8}$. Discutiremos aqui, tendo em mente um artigo de Pedro Monteiro publicado na revista Trajectos em 2003, se tais espaços devem ou não ser assim classificados. Monteiro considera fundamental o pensamento de Marc Augé para analisar esses espaços, embora não concorde com a classificação de "não lugar" em relação aos centros comerciais e em particular ao Amoreiras Shopping Center. $\mathrm{O}$ autor começa sua argumentação com uma definição geral de centro comercial: espaço público privatizado, forte visibilidade física, presença de um sujeito enunciador, lugar de comu-
7. Talvez essa ambiguidade explique o seu apoio ao projeto de Koolhaas para Les Halles em Paris.
8. Os centros comerciais surgiram tardiamente na Europa do Sul e, em Portugal, apenas em meados dos anos de 1980, apresentando uma variedade de formatos (cf. Cruz, 2009). 
nicação. Chama a atenção para a existência de uma diversidade de centros comerciais, mais especificamente para o Amoreiras Shopping Center. Para ele, a primeira questão é perceber o que atrai os indivíduos até os centros comerciais, defendendo que "há uma lógica de validação desses espaços que ultrapassa a lógica estrita do consumo, e talvez até a lógica estrita do lazer" (Monteiro, 2003, p. 9).

A partir da definição de Augé de "não lugar" como espaços não identitários, não históricos e não relacionais, Monteiro defende que o centro comercial das Amoreiras é um lugar porque constrói uma identidade que passa por sua localização em um espaço. Um cartaz nesse centro traz a inscrição "centro histórico da cidade", o que revela a busca de uma simbologia que ultrapassa a simples esfera do consumo. $\mathrm{O}$ autor compara a história (contada e/ou vivida) com as "narrativas históricas" que se constroem tendo em conta o local onde os centros foram inseridos, a história do país ou a arquitetura inovadora da sua construção. Essa história construída aparece via publicidade, imagens, esteriótipos, mas tem, para o autor, uma verdade simbólica: "Como espaço simbolizado, o centro comercial carece a um só tempo de passado e de futuro. É isso que o faz balancear entre a busca de uma identidade com raízes (profundidade histórica) e a abertura ao exterior e à modernidade: entre a programação cultural e histórica (memória) e o culto da novidade comercial" (Idem, p. 13).

Pedro Monteiro transforma o Amoreiras Shopping Center em um "novo lugar", partindo da definição de lugar antropológico utilizada por Augé, valorizando positivamente aquilo que o autor deprecia. Assim, quando identifica os grandes centros comerciais como "não lugares", Augé critica essa "construção da história" através da publicidade e das imagens que procuram formar virtualmente a sua própria memória. Ora, a memória é algo que se vai construindo na relação entre as pessoas e as coisas. Não pode ser algo que vem de fora como uma "boa imagem". E o centro comercial é antes de tudo um local de consumo, cuja memória se constrói de forma cíclica - Natal, dia dos pais, dia dos namorados etc. -, tendo o consumo como elemento central.

A identidade desse espaço é feita através da semelhança com outros espaços de outras partes do mundo "civilizado". Corresponde de fato a uma arquitetura inovadora e igual a outras arquiteturas dos países ocidentais: "De um lado ao outro do planeta, os aeroportos, os aviōes, as cadeias hoteleiras colocam sob o signo do idêntico e do comparável a diversidade geográfica e cultural" (Augé, 2003, p. 53). O que nos atrai neles é o que 
vem de fora, é a sua funcionalidade e não alguma relação com o nosso país, a nossa cultura.

Para a análise desses locais, é interessante entender as relações que ali se estabelecem entre nós e os outros: a ausência de uma relação com os empregados (que estão em constante mudança); a impossibilidade de "caminhar" procurando novos percursos; a relação com o ambiente (ar, luz, sol); a homogeneidade dos frequentadores (não há mendigos, guardadores de carros, toxicodependentes) etc. Como refere Sennett (1989), uma das preocupações dos projetos dos centros comerciais é a quase inexistência de locais onde as pessoas possam se sentar por muito tempo para conversar?. $\mathrm{O}$ tipo de ação social pretendida nesses locais está associado à circulação e ao consumo, ou seja, trata-se de um uso econômico e não político ou social.

Voltemos a De Certeau e à ideia de caminhada como "retórica do andar", em que o transeunte escolherá seus percursos e irá se apropriando do espaço. Pensemos como isso é possível quando caminhamos em um centro comercial: ali escolhemos o quê em detrimento de quê? Que sensaçóes temos quando passamos pela Zara ou pela Lacoste? Que surpresa temos quando olhamos para as lojas que se seguem umas às outras, todas mais ou menos iguais? Enfim, que tipo de caminhada fazemos quando circulamos em um centro comercial que não seja a do consumo, ou que não esteja "suspensa" pelo consumo?

Segundo Marc Augé, o centro comercial não é um espaço relacional, é um espaço de consumo, de lazer e de informação. Pedro Monteiro concorda com esse aspecto, mas considera que essas características fazem parte dos lugares antropológicos, enquanto Marc Augé as considera "não lugares": "Espaços onde se coexiste ou coabita sem vivermos juntos, onde o estatuto de consumidor ou de passageiro solitário passa por uma relação contratual com a sociedade" (Augé, 1994a, p. 157).

Essa "relação contratual com a sociedade" começa a ser visível quando pensamos nas transformações do "homem público" nas grandes capitais do século XIX. Ainda que brevemente, abordaremos aqui o clássico livro de Richard Sennett, $O$ declínio do homem público $^{10}$, para entender melhor esse processo de mudança. É nas alterações que o comércio de varejo foi sofrendo ao longo do século XIX que Sennett procura algumas das causas da transformação da vida pública. Referimo-nos concretamente ao aparecimento do bazar, que tem o centro comercial como seu sucedâneo no século XX e que surge nas principais cidades europeias na segunda metade do século XIX, em um período de grande crescimento demográfico. Trata-se de um conjunto de

9. Em Portugal há, no entanto, diferenças entre os grandes e os pequenos centros comerciais. Nestes, podemos encontrar grupos de indivíduos, muitas vezes jovens e aposentados, que permanecem o tempo necessário à volta de uma mesa e de um café para que uma conversa se desenrole.

10. Edição brasileira: São Paulo, Companhia das Letras, 1988 (N. E.). 
lojas concentradas em um edifício, que com o tempo se expandiu e passou a ocupar os espaços limítrofes. Georges Simenon assim descreve o Grand Bazar de Liège: "Na praça Saint-Lampert, os candeeiros mais numerosos, mais brilhantes do Grand Bazar, cujas instalaçôes não param de crescer e já devoraram dois quarteirōes de casas. As bonitas montras, as portas de cobre que deslizam sem fazer barulho e aquele bafo quente, tão particular, que se estende até ao meio do passeio" (Simenon, [1931] 2006, p. 12). Segundo Richard Sennett, as transformações da vida pública do século XIX estão profundamente ligadas ao modo como o comércio de varejo se transformou nas capitais do século XIX. O bazar, que substituirá os mercados ao ar livre e as pequenas lojas, era o exemplo do local de encontro de um número cada vez maior de pessoas, mas onde se estabeleciam cada vez menos relaçóes de sociabilidade: "O surgimento do bazar, que pode parecer um tema mundano, é de fato a forma disfarçada do verdadeiro paradigma de como o domínio público enquanto um intercâmbio ativo permitiu que a vida das pessoas experimentasse o público mais intensamente e de forma menos sociável" (Sennett, [1974] 2002, p. 316). O Bazar Bon Marché, aberto em Paris em 1852, baseava-se em três ideias originais: a margem de lucro sobre cada artigo seria pequena, mas o volume de vendas seria grande; os preços dos produtos seriam fixos e marcados; qualquer pessoa poderia entrar na loja e não se sentiria obrigada a comprar (cf. Idem, ibidem). A primeira ideia pressupóe uma forte ligação entre o bazar e a fábrica, já que era necessário fabricar muitos produtos iguais a preços baixos, a serem comprados por um número cada vez maior de pessoas. Por outro lado, vender cada vez mais produtos, embora a preços mais baixos, só seria possível se a classe trabalhadora e a burguesia emergente tivessem um aumento de nível de vida, permitindo um aumento de consumo. Para isso, era necessário que o maior número de pessoas tivesse acesso ao bazar, o que implicava construir novas estradas e oferecer mais transporte público. As ruas sinuosas e estreitas da antiga cidade não permitiam rápidos deslocamentos, "calculava-se que, devido às estreitas e meandrosas estradas de Paris nos princípios do século XIX, uma viagem a pé que hoje dura quinze minutos naquela época requeriria uma hora e meia" (Idem, p. 319). A construção dos grandes bulevares em Paris nos anos de 1860 (por Haussman), assim como a criação de um sistema de transportes em Paris e Londres, tornou mais fácil a mobilidade dentro da cidade.

O segundo aspecto, os preços fixos, veio a acabar com uma prática social que fazia parte do jogo de interações que os atores sociais, funcionando de fato como atores, representavam na vida cotidiana. A rua era de certo 
modo o palco de um teatro onde o ato de comprar não era algo passivo e silencioso, mas resultava de uma encenação cujas regras eram conhecidas por todos e onde a capacidade de representação, argumentação e sedução tinha o seu lugar.

O terceiro aspecto, a não obrigatoriedade de comprar, suprimia o constrangimento da "obrigação" da compra ao entrar em uma loja. Como refere Sennett (2002), na Paris do Antigo Regime e do início do século XIX, entrar numa loja significava que se iria comprar algo. O bazar acabou com esse constrangimento e propôs uma nova postura diante do consumo, permitindo usufruir do espaço, ver os produtos, desejá-los, mas sem o sentimento de obrigação da compra - trata-se da "liberdade" do consumidor. Mas essa liberdade foi contornada por estratégias adotadas pelos comerciantes, que procuravam, pelo seu lado, estimular as pessoas a consumir ${ }^{11}$. Walter Benjamim, no seu texto célebre "Paris, capital do século XIX", refere-se à figura do flaneur que deambula no meio da multidão, afastando-se dos espaços familiares. O flaneur era apenas aquele que olhava, mas acabou por participar do jogo do consumo: "O grande armazém de comércio é o cenário da última deambulação do flaneur" (Benjamin, 2001, p. 74).

A substituição do "mercado de rua" pelo bazar no século XIX, associada à diminuição dos custos e à existência de uma maior diversidade de produtos, e mais tarde do bazar pelo centro comercial, foram transformando o espaço público em um espaço cada vez mais de consumo. É exatamente essa diminuição de relações sociais no espaço público, essa passividade do cidadão, que caracteriza os não lugares de Marc Augé.

\section{Espaço de fluxos e não lugares: entre Manuel Castells e Marc Augé}

Manuel Castells tem um percurso de investigação bem diferente de Marc Augé, mas que, como ele, defende que a organização do espaço é um elemento crucial para a compreensão da sociedade contemporânea: "ao contrário da maioria das teorias sociais clássicas, que supõem o domínio do espaço pelo tempo, proponho a hipótese de que o espaço organiza o tempo na sociedade em rede"12 (Castells, 2002, p. 493). Este ponto de partida comum, que ressalta a importância do espaço na organização social, justifica que nos detenhamos na noção de "espaço de fluxos" desenvolvida por esse autor.

Castells analisa a nova lógica espacial, resultante da interação entre tecnologia, sociedade e espaço, denominando-a "espaço de fluxos"13. Esse espaço, que se constitui a partir de um conjunto de serviços avançados - finança,
11. Trata-se da criação de um fetichismo da mercadoria. A questâo colocada por Sennett é a de perceber por que é que esse fetichismo teve êxito: "Um dos efeitos principais do capitalismo sobre a vida pública foi mistifcar os fenômenos públicos, mas a mistificação só poderia ter êxito se as pessoas desejassem crer que os objetos estavam ataviados com atributos de caráter humano" (Sennett, 2002, pp. 327-328).

12. Esta posição foi defendida também por Michel Foucault em 1967, em uma conferência proferida no Cercle d'Études Architecturales: "Em todo o caso, creio que a inquietude dos dias de hoje está relacionada, sem margem de dúvidas, muito mais com o espaço do que com o tempo" (2005, p. 2).

13. O autor descreve tais espaços a partir da combinação de três suportes materiais: o primeiro corresponde a um circuito de impulsos eletrônicos possibilitados pelos equipamentos de tecnologia de informaçāo; o segundo é constituído pelos nós e centros de comunicação dessa rede, onde as decisōes são tomadas em nível global; o terceiro corresponde à organização espacial das elites administrativas que exercem funçōes diretivas. 
seguros, bens imobiliários, projetos, marketing, pesquisa e desenvolvimento, inovação científica etc. -, materializa-se em uma organização espacial em torno de centros de controle e comando, aquilo que corresponde à ideia de "cidade global" (cf. Sassen, 2001), em que algumas cidades mundiais dominam as finanças internacionais e grande parte dos serviços empresariais e de consultadoria, de âmbito internacional, constituindo-se assim uma nova elite "política-empresarial-tecnocrática” (Castells, 2002, p. 497).

O espaço de fluxos - de capital, de informação, de tecnologia, de interação organizacional, de imagens, sons e símbolos (cf. Idem, p. 535) - é o oposto de uma organização espacial historicamente enraizada, a que Castells chamou de "espaço dos lugares": "Um lugar é um local cuja forma, função e significado são independentes dentro das fronteiras da contiguidade física" (Idem, p. 549). Como exemplo, refere Belleville, em Paris, bairro de imigrantes que o autor conhece desde 1962 e que, em 1995, continua a ser um lugar, apesar de ter se transformado física e socialmente.

Os novos imigrantes (asiáticos, iugoslavos) uniram-se ao grupo mais antigo de judeus tunisinos, muçulmanos do Magreb e pessoas do sul da Europa. Verificaram-se diversos processos de renovação urbana na década de 1970, que transformaram o bairro sob o ponto de vista arquitetônico e social. Alguns migrantes pobres foram obrigados a abandonar o lugar devido aos processos de renovação (cf. Pinson e Bekkar, 1999) e novas famílias da classe média, sobretudo jovens, mudaram-se para lá por causa da vitalidade urbana. Em Lisboa, a Mouraria apresenta algumas semelhanças com Belleville. Apesar de se situar no centro da cidade e ser um bairro muito mais antigo, ali os autóctones e os migrantes convivem em um espaço marcado pela diversidade étnica: "A intensa atividade comercial que caracteriza o bairro tem uma forte componente étnica, que remonta aos grupos pioneiros de migrantes de origem indiana que se estabeleceram nesta área, entre 1976-1980, aos quais se seguiram outros grupos migrantes, sendo este um espaço de confluência de pessoas e de grupos sociais heterogêneos" (Mendes, 2012, p. 7). Manuela Mendes, no artigo referenciado, chama a atenção para o perigo de se repetir na Mouraria um processo de renovação urbana semelhante ao de Belleville, o que inflacionaria os preços da habitação, implicando processos de gentrification em que os mais pobres são afastados do seu hábitat tradicional. Mas, segundo Castells, em Belleville ainda estamos diante de uma urbanidade múltipla, em que diferentes comunidades étnicas coexistem pacificamente, embora com algumas tensões: "entre a casa e o mundo existe um lugar chamado Belleville" (Castells, 2002, p. 552). 
O "espaço dos lugares" opõe-se ao "espaço dos fluxos", projetado para o mundo, sem raízes no lugar. O "espaço dos fluxos”, frisa Castells, não é a única lógica espacial das nossas sociedades, mas é a dominante, porque corresponde aos interesses representados pela elite empresarial tecnocrática e financeira com exigências espaciais específicas. Manuel Castells, partindo da importância dessas exigências, mostra como elas estão relacionadas com a apropriação e o controle do espaço onde se instalam, constituindo comunidades simbólica e espacialmente segregadas.

As elites criam um "estilo de vida" que é semelhante em todo o mundo, assim como são semelhantes os espaços por elas habitados: hotéis internacionais com decoração e design igual em todo o planeta, salas vip de aeroportos, restaurantes, condomínios fechados etc. Há um "estilo de vida" associado a esses espaços que passa pela utilização de certos objetos, roupas, preocupaçóes: o uso do computador portátil em viagens, a prática do jogging, a dieta, a combinação de trajes sociais e roupas esportivas etc. Tudo isso são símbolos de uma cultura internacional, sem ligação com uma sociedade específica. Assiste-se à criação de um "espaço internacional" localizado no centro das grandes cidades, segregado (pelo preço e segurança), homogêneo e sem raízes culturais. Estamos diante de um espaço desenraizado, virtual, apropriado por um conjunto de indivíduos também eles desenraizados. Richard Sennett, ao analisar a questão da identidade, partindo das relações dos indivíduos com o espaço e o trabalho, refere-se à situação de dois grupos: os emigrantes e a nova elite da globalização. Esses grupos, apesar de suas situações econômicas, sociais e culturais diferentes, possuem muita dificuldade de se identificar com o espaço que habitam. Por outro lado, e esse é o aspecto que mais nos interessa aqui, a nova elite da "cidade global" controla, gere e investe em restaurantes, discotecas, apartamentos, mas tem pouco interesse em controlar o que ocorre em hospitais, escolas ou outros domínios públicos da cidade (cf. Sennett, 2000, p. 181). Há uma espécie de desligamento do espaço físico e social onde se habita, até porque ele é transitório, e procuram-se pequenos "nichos" que são iguais em qualquer parte do mundo. Como afirma Castells, “as elites são cosmopolitas e os indivíduos locais" (2002, p. 540).

Os pontos de contato e de conflito entre essas duas abordagens, que partem de lógicas, pressupostos e comunidades científicas muito diferentes, certamente giram em torno da noção de espaço: é semelhante o que Castells chama de "espaço dos lugares" e Augé de "lugares antropológicos", onde a experiência dos indivíduos está vinculada aos espaços que eles percorrem e habitam, a sua cultura, a sua história. Quanto à ideia de "espaços de fluxos" 
14. Trata-se de um conjunto de construções arquitetônicas assinadas por arquitetos mundialmente célebres - a pirâmide do Louvre, o Museu Guggenheim etc. (cf. Augé, 2003, p. 75).

15. Ediçăo brasileira: Rio de Janeiro, Bertrand Brasil, 1997 (N. E.).

16. Lisboa é um bom exemplo de cidade retratada nas canções (o fado), na pintura, na poesia, no romance: lugar onde os indivíduos e o espaço ainda mantêm um laço. e de "não lugar", as semelhanças não são tão evidentes. Quando Castells se refere ao "espaço dos fluxos", define-o não só como um espaço geográfico ligado às Novas Tecnologias de Informação (NTI) e à globalização, mas também como um espaço social de uma elite dirigente, ligado ao poder e à riqueza. Essa relação entre espaço geográfico e classe social não é tão clara em Marc Augé, pois não há sempre uma classe específica ou grupo social associado aos "não lugares". No entanto, em Letempsen ruines, Augé, referindo-se a uma arquitetura que chamou de "singularidades ${ }^{14}$ e dos não lugares", associou-a a uma minoria rica esclarecida. Trata-se de um espaço virtual, de uma utopia que é hoje apropriada por essa minoria e não pela humanidade: "Os não lugares têm a beleza do que poderá vir a ser. Do que ainda não é. Do que, um dia, talvez, terá lugar” (Augé, 2003, p. 135).

Por outro lado, podemos dizer que alguns "não lugares" (grandes centros comerciais, hipermercados, autoestradas) são os "espaços de fluxos" de uma classe média europeia cada vez mais empobrecida, do "homem médio" (cf. Mauss, [1950] 2004). Espaço onde quase não se estabelecem relações sociais e que ao mesmo tempo promove a interação entre as elites.

\section{A cidade, a "grande cidade"}

Em Por uma antropologia dos mundos contemporâneos ${ }^{15}$, Marc Augé afirma que "a cidade é um mundo", o que significa que ela contém simultaneamente um espaço simbolizado e utilizado pelos indivíduos e outro que reflete todos os traços do mundo atual. É nesse jogo, entre interior/exterior, comunidade/ sociedade, que a cidade emerge.

A cidade dos indivíduos é o mundo onde cada um mantém relação com o lugar a partir da memória, do cotidiano, das experiências vividas. A identificação de cada pessoa com um lugar sobressai dessa ligação forte com um território. É também aí que surge a cidade do transeunte que inventa os seus percursos ao andar (cf. De Certeau, 1980), e a cidade dos poetas e escritores. As grandes cidades (Berlim, Paris, Nova York) aparecem na literatura, na poesia, e são tema de muitas canções populares ${ }^{16}$.

Para além da liberdade e da poesia que a cidade permite, ela é o reflexo também das transformaçôes sociais e econômicas. O mundo atual é o da globalização, que tem como pano de fundo a mobilidade e o consumo. Os "não lugares" de Marc Augé são exatamente os meios que permitem a circulação de tudo e de todos, "são não lugares, na medida em que sua vocação primeira não é territorial, não é a de criar identidades singulares, relações 
simbólicas e patrimônios comuns, mas antes de facilitar a circulação (e, dessa maneira, o consumo) em um mundo com as dimensões do planeta" (Augé, 2003 , p. 85). A construção de espaços de circulação e consumo, desligados do território e das pessoas que os habitam, implica dois grandes riscos segundo Augé: a uniformidade e a generalização do espaço urbano.

A primeira é perceptível pelo conjunto de edifícios semelhantes encontrados em todo o mundo e que se referem aos espaços extraterritoriais, espaços do déjà-vu (cf. Idem, ibidem), porque se parecem todos uns com os outros: estamos exatamente no mundo dos "não lugares", onde o viajante não se sente nem estrangeiro nem "em sua casa", e o autóctone sente-se estranho, residente, perdendo a singularidade do seu território.

Ao mesmo tempo, assiste-se a uma generalização do urbano, um alastrar das cidades através da construção de edifícios residenciais, zonas industriais e comerciais etc., "que não têm vocação estritamente local mas antes regional e marcam a paisagem com o cunho de uma incrível monotonia, 'desqualificando-a’ no sentido estrito do termo, já que não é possível qualificá-la nem como urbana nem como rural" (Augé, 1994a, p. 165).

Esses dois movimentos, cujo objetivo parece ter sido o de resolver problemas de circulação, consumo e comunicação das populações, correspondem, segundo Marc Augé, antes à vontade de facilitar a circulação e o consumo de um mundo globalizado cujo território é cada vez mais o planeta (cf. Augé, 2003, p. 85). É nesse processo que se constroem os "não lugares", que vão destruindo a cidade moderna e construindo cada vez mais espaços agrestes. Em Portugal, temos bons exemplos desse tipo de urbanização quando observamos os arredores de uma cidade média (Portalegre, Castelo Branco etc.), onde avistamos uma paisagem que já não é nem rural nem urbana, coberta de grandes armazéns, com grandes parques de estacionamento, grandes vias de circulação, rodeado de edifícios residenciais entremeados por resquícios de zonas verdes. Esses espaços permitem o aumento do consumo para um grande número de pessoas, mas também estão associados a uma vida urbana cada vez mais agressiva: distância dos locais de trabalho, segregação nos bairros, desemprego, problemas econômicos associados à compra de casa etc.

Como Marc Augé, Manuel Castells também defende que nas cidades das sociedades desenvolvidas a tendência predominante é a construção de espaços de consumo, circulação e comunicação. Ele se refere à construção de "cidades globais" (cf. Sassen, 2001), marcadas por "um horizonte de espaço de fluxos a-histórico em rede, visando impor a sua lógica nos lugares 
17. Em 1997, os habitantes reagiram ao projeto da World City Fair (que correspondia à lógica global dos negócios internacionais), votando no comediante de televisão Aoshima, que se lançou como candidato independente, sem o apoio dos partidos políticos ou círculos financeiros, e adotou como lema de campanha cancelar a World City Fair.

18. Ficam aqui apenas umas breves notas sobre um tema tão complexo e extenso. segmentados e espalhados, cada vez menos relacionados uns com os outros, cada vez menos capazes de compartilhar códigos culturais" (Castells, 2002, p. 555). Mas, embora essa seja a tendência mais provável, há cidades, segundo Castells, que recuam diante dos riscos da lógica econômica subjacente à "cidade global”. Tóquio passou por um período de reurbanização durante os anos de 1980, obedecendo a lógica da cidade global. No entanto, governantes e habitantes sempre se mostraram sensíveis tanto ao perigo da perda da identidade e da essência histórica, quanto à lógica instrumental da cidade global ${ }^{17}$.

\section{A arquitetura contemporânea e as cidades ${ }^{18}$}

Marc Augé e Manuel Castells, ao pensarem a cidade a partir das noções de "espaço de fluxos" e "não lugares", têm em mente não só uma dimensão social, política e econômica, subjacente ao processo de globalização, mas também a análise dos espaços urbanizados e arquiteturados da sociedade contemporânea.

Para além dos dois riscos já referidos, que resultam da expansão e da homogeneidade do espaço urbano, encontramos em Augé certa ambiguidade na análise da arquitetura contemporânea, mantendo atitude prudente, de certo modo distante, e ressaltando ora aspectos positivos, ora negativos.

Ao falar de Paris, ele se refere a alguns edifícios recentes, como a nova sede do ministério das finanças, o Palácio Bercy e a Biblioteca Nacional, como espaços com os quais se sente relativamente familiarizado. Por outro lado, ele teme a construção de novos bairros nas margens do Sena, onde há espaçadamente ora um barco, ora uma casa velha, ora uma clareira. Teme que as novas construções sigam o modelo das "cidades genéricas", onde todos os edifícios são iguais, quer estejam em Tóquio, Berlim ou Paris. No entanto, Augé deixa uma margem de dúvida ao considerar muito difícil julgar esses temas: "é preciso dar tempo à cidade, e são os transeuntes de amanhã que poderão dizer se Paris continua sempre Paris transformandose" (Augé, 2003, p. 127).

Castells desenvolve com menos ambiguidade a sua ideia sobre a arquitetura contemporânea. Distingue duas formas de arquitetura: a das "cidades globais", que corresponde à arquitetura dos "espaços de fluxos", e a "arquitetura ecológica”, que pode estar surgindo.

A arquitetura das "cidades globais" é pós-moderna, que representa o fim de todos os sistemas de significados, uma arquitetura a-histórica, a-cultural: 
Deste modo, a arquitetura escapa à história e à cultura de cada sociedade e torna-se refém do novo e admirável mundo imaginário das possibilidades, ilimitadas, que sublinham a lógica transmitida pelo multimédia: a cultura da navegação eletrônica, como se pudéssemos reinventar todas as formas em qualquer lugar, apenas sob a condição de mergulhar na indefinição cultural dos fluxos do poder. O encerramento da arquitetura numa abstração histórica é a fronteira formal do espaço de fluxos (Castells, 2002, p. 543).

Para além da arquitetura do "imaginário mundo novo", a arquitetura dos "espaços de fluxos" manifesta-se também em outro tipo de edifícios que correspondem aos "não lugares” de Marc Augé. Trata-se de uma arquitetura cujas "formas são tão puras, tão neutras, tão diáfanas, que não pretendem dizer nada" (Idem, p. 546). Castells a chama de "arquitetura da nudez", "a sua mensagem é o silêncio"19. Afirma que deveriam ser construídos grandes e luxuosos palácios para os novos senhores, mostrando assim a existência real dessa nova classe de dirigentes, quase invisível, no meio da imaterialidade do "espaço de fluxos". O segundo tipo de arquitetura que poderia ter lugar hoje corresponderia, em um movimento oposto, a construir a partir das raízes dos lugares, segundo a cultura dos indivíduos, aproximando-se de uma "arquitetura ecológica" 20.

Segundo Montaner, a sensibilidade da arquitetura contemporânea ao lugar (como espaço empírico, concreto, existencial e delimitado) é um fenômeno recente: tem a ver com a cultura organicista desenvolvida na obra de Frank Lloyd Wright e as propostas dos arquitetos nórdicos encabeçados por Alvar Aalto (cf. Montaner, 2001, p. 34). Há uma "dissolução contemporânea do lugar", devido ao surgimento de três tipos de espaço: mediático, "não lugar" e ciberespaço. Segundo o autor, hoje se verifica uma simultaneidade de espaços/antiespaços, lugares/não lugares, que se entrelaçam, interpenetram e convivem. Ele defende, como Castells, uma arquitetura para o presente, referindo-se à "arquitetura ecológica”, que parte de uma ecologia do já construído, gerando um reequilíbrio entre os seres humanos e o seu ambiente: "O desafio atual consiste em demonstrar que a arquitetura ecológica, além de ser necessária globalmente e correta socialmente, pode ser muito atraente do ponto de vista estético, conceitual e cultural" (Idem, p. 196). Trata-se de uma arquitetura que aceita a diversidade cultural, mas fomenta a criação de espaços comunitários.

Pensar a arquitetura é também pensar o tipo de sociedade que queremos construir, ou seja, ter em conta uma dimensão social e política. Voltemos
19. O autor dá como exemplos o aeroporto de Barcelona, projetado por Bofill, e a nova estação AVE de Madri, de Rafael Moneo (cf. Castells, 2002, pp. 546-547).

20. Termo não é utilizado por Marc Augé, mas está subjacente à ideia de "lugar antropológico". 
a Marc Augé e à sua imagem da "cidade é um mundo", em que o autor se refere a várias situaçôes da vida cotidiana na cidade - o tempo passado nos transportes, os jovens que erram pelos "bairros perigosos", os guetos étnicos, desemprego etc. -, mostrando a ligação entre certo tipo de sociedade e certo tipo de cidade. Como afirma o autor, se é verdade que não é o arquiteto, nem o urbanista, nem o sociólogo ou antropólogo que podem resolver os problemas sociais e econômicos dos indivíduos que habitam a cidade, também é verdade que "um urbanismo irrefletido e uma arquitetura feia são um prejuízo na nossa relação com o mundo" (Augé, 1994a, p. 172).

Henri Lefebvre defendia, já em 1974, que a dominação do espaço natural pela técnica caracteriza a sociedade moderna - "uma autoestrada, que brutaliza a paisagem e o país: corta, como se fosse uma grande faca, o espaço" (Lefebvre, [1974] 2000, p. 191). Por outro lado, a autoestrada pôde aproximar pessoas que estavam fisicamente distantes. Mas a possibilidade de estreitar o tempo e o espaço será uma vantagem que justifique a destruição de seu entorno? Augé, referindo um trabalho de Jean-Paul Dollé, dá o exemplo da construção de uma grande autoestrada em Marselha, que atravessa um bairro da cidade:

O que esperar daqueles que imaginaram, em Marselha, construir essa autoestrada [... ] não oferecendo como horizonte aos que moram nos andares mais baixos senão o tabuleiro das vias suspensas e a parte de trás dos carros? Nada a não ser o desprezo mais total dos seres humanos, a vontade plenamente deliberada de os tratar como coisas, de agredir os seus sentimentos e de atacar a sua integridade corporal e física (Augé, 1994a, pp. 166-167).

Construir uma autoestrada não é uma decisão técnica, é antes de tudo uma decisão política. Se por um lado ganhamos tempo, por outro "perdemos o espaço", brutalizando a paisagem e tornando também mais brutal a vida de muitas pessoas. É por isso que Marc Augé faz um alerta: "Pedir aos urbanistas e aos arquitetos que se mantenham fiéis à história de todos e tornem possível a de cada um é pedir-lhes que reconstruam espaços onde se possam conjugar o sentido do lugar e a liberdade do não lugar" (Idem, pp. 174-175). 


\section{Referências Bibliográficas}

AugÉ, Marc. (1989), Domaines et chateau. Paris, Éditions du Seuil. - (1994a), Pour une anthropologie des mondes contemporains. Paris, Aubier. . (1994b), Le sens des autres. Actualité de l'anthropologie. Paris, Fayard. - (1998), A guerra dos sonhos. Oeiras, Celta. . (2003), Le temps en ruines. Paris, Galilée. . ([1992] 2005), Não lugares: introdução a uma antropologia da sobremodernidade. $1^{\text {a }}$ edição francesa. Lisboa, 90 Graus. . ([2003] 2006), Para que vivemos? 1a edição francesa. Lisboa, 90 Graus. . (2011), Où est passé l'avenir? Paris, Éditions du Seuil.

Bauman, Zygmunt. (2007), Vida de consumo. Madri, Fondo de Cultura Económica de España.

Benjamin, Walter. (2001), "Paris, capital do século XIX”. In: Fortuna, Carlos (org.). Cidade, cultura e globalização. Oeiras, Celta, pp. 67-80.

Castells, Manuel. (2002), A sociedade em rede. Lisboa, Fundação Calouste Gulbenkian, vol. 1.

Cruz, Sofia Alexandra. (2009), "Novas 'catedrais' de trabalho: experiências laborais em centros comerciais". Actas do v Congresso Português de Sociologia. Universidade do Minho, 12-15 de maio de 2004.

De Certeau, Michel. (1980), Linvention du quotidian: arts de faire. Paris, Union Général d'Éditions.

Elias, Norbert. (1999), Introdução à sociologia. Lisboa, Edições 70.

Foucault, Michel. (2005), "Espaços outros”. Revista de Comunicação e Linguagens. Lisboa, Relógio d'Água, n. 34/35, jun.

Giard, Luc \& MAYOL, Pierre. (1980), Linvention du quotidian: habiter, cuisiner. Paris, Union Général d'Éditions.

Lefebvre, Henri. ([1974] 2000), La prodution de l'espace. Paris, Anthropos.

LÉVI-STrauss, Claude. (1987), Mito e significado. Lisboa, Edições 70. . ([1955] 1993), Tristes trópicos. Lisboa, Ediçôes 70.

LyNCH, Kevin. (2007), A boa forma da cidade. Lisboa, Edições 70.

Mauss, Marcel. ([1950] 2004), Sociologie et anthropologie. Paris, Presses Universitaires de France.

Mendes, Maria Manuela. (2012), "Bairro da Mouraria, território de diversidade: entre a tradição e o cosmopolitismo". Sociologia, número temático, pp. 15-41.

Montaner, Josep Maria. (2001), A modernidade superada. Barcelona, Gustavo Gili.

Monteiro, Pedro. (2003), "Espaço público no centro comercial: o Amoreiras como porta de entrada”. Trajectos, 3: 9-18. 
Pinson, Daniel \& BekKar, Rabia. (1999), "Urban renewal, ethnicity and social exclusion in France". In: Khaker, Abdul, Somma, Paola \& How, Thomas (eds.). Urban renewal, ethnicity and social exclusion in Europe. Inglaterra/Estados Unidos, Ashgate Publishing, pp. 103-125.

SASSEn, Saskia. (2001), The global city: New York, London, Tokyo. New Jersey, Princeton University Press.

Sennett, Richard. (1989), "The civitas of seeing”. Places, 5 (4): 82-84. . (2000), "Street and office: two sources of identity". In: Hutton, Will \& GIDDENS, Anthony. On the edge, living with global capitalism. Londres, Jonathon Cape, pp. 175-190. . ([1974] 2002), El declive del hombre público. Barcelona, Península.

Simenon, Georges. ([1931] 2006), Pedigree. Lisboa, ASA.

Simmel, Georg. ([1908] 1992), Sociologie. Paris, Presses Universitaires de France. . ([1908] 2004), Fidelidade e gratidão e outros textos. Lisboa, Relógio d'Água.

Weber, Max. ([1922] 1971), Économie et societé. Paris, Plon, vol. 1. 


\section{Resumo}

Lugares e não lugares em Marc Augé

O termo "não lugares", utilizado por Marc Augé pela primeira vez em 1992 em seu livro Não lugares, acompanha a sua obra como se incorporasse algo fundamental para a compreensão da sociedade contemporânea. Ao longo deste artigo procuramos clarificar o sentido, ou os vários sentidos, que Marc Augé lhe dá, analisando entre outros aspectos a discussão sobre os centros comerciais como "não lugares" e procurando semelhanças e diferenças entre os "não lugares" e o "espaço de fluxos" (Castells). A pergunta que parece estar sempre subjacente ao pensamento de Marc Augé é saber de que forma os "não lugares" podem provocar uma perda de nós mesmos como grupo, como sociedade, passando a prevalecer o indivíduo isolado ou "solitário".

Palavras-chave: Não lugares; Sobremodernidade; Espaço de fluxos; Indivíduo solitário.

\section{Abstract}

\section{Marc Augés places and non-places}

"Non-places", a term first used by Marc Augé in 1992 in his book Non-Lieux, runs through his work as the embodiment of something fundamental to understanding contemporary society. In this article we try to clarify the meaning, or multiple meanings, attributed by the author to this term, examining among other things the discussion on the shopping centre as a "non-place" and looking for similarities and differences between "non-places" and the "space of flows" (Castells). The question that always seems to underpin Marc Augé's thought is whether and how non-places"' can cause us to lose ourselves as a group, a society, such that isolated 'lone' individuals come to prevail. Keywords: Non-places; Supermodernity; Flows of space; Isolated individual.

Texto recebido em 31/7/2012 e aprovado em 20/8/2013.

Teresa Sá é professora auxiliar no Departamento de Ciências Sociais e do Território da Faculdade de Arquitectura da Universidade Técnica de Lisboa. E-mail: teresavsa@gmail.com. 